\title{
О ПРОЯВЛЕНИИ ПРОЦЕССОВ ИНДУКЦИОННОГО СТАНОВЛЕНИЯ И ВЫЗВАННОЙ ПОЛЯРИЗАЦИИ ПРИ РАБОТЕ С ОСЕВОЙ И СИММЕТРИЧНОЙ ЭЛЕКТРИЧЕСКИМИ УСТАНОВКАМИ
}

Агеенков Е. В., Ситников А. А., Пестерев И. Ю., Попков А. В.

\begin{abstract}
Аннотация
Рассмотрено проявление электромагнитного (ЭМ) сигнала над проводящей поляризующейся Землёй на измерительных линиях, расположенных на оси источника и внутри него (для симметричной установки Шлюмберже).

Исследование основано на численном эксперименте. Проводились расчёты ЭМ отклика от одномерных моделей. Учёт поляризуемости реализован введением частотно зависимого удельного электрического сопротивления моделью Коула-Коула.

Описаны результаты численного эксперимента по расчёту сигнала становления над проводящей поляризующейся средой на 2-х и 3-х электродных заземлённых измерительных линиях, расположенных в осевой и экваториальной области источника - заземлённая линия. Показано различие проявления индуктивного сигнала (становления поля) и сигнала вызванной поляризации, связанного с гальваническим и вихревым током.
\end{abstract}

\section{Ключевые слова:}

электромагнитные зондирования, заземлённая линия, трёх-электродная заземлённая измерительная линия, зондирования проводящих поляризующихся сред, модель Коула-Коула, индукционно вызванная поляризация, ВПИ, гальванически вызванная поляризация, ВПГ, прямая задача для проводящей поляризующейся среды 


\title{
О ПРОЯВЛЕНИИ ПРОЦЕССОВ ИНДУКЦИОННОГО СТАНОВЛЕНИЯ И ВЫЗВАННОЙ ПОЛЯРИЗАЦИИ ПРИ РАБОТЕ С ОСЕВОЙ И СИММЕТРИЧНОЙ ЭЛЕКТРИЧЕСКИМИ УСТАНОВКАМИ
}

\author{
Е. В. Агеенков ${ }^{1,2}$, А.А. Ситников ${ }^{1}$, И.Ю. Пестрев ${ }^{1}$, А.В. Попков ${ }^{1}$ \\ ${ }^{1} О О О$ «Сибирская геофизическая научно-производственная компания», 664044, \\ Иркутск, ул. Щапова, 14, Россия \\ ${ }^{2}$ Кафедра Прикладной геологии, геофизики и геоинформационных систем (ПГГиГС) \\ Иркутского Национального Исследовательского Технического Университета (ИРНИТУ), \\ 664074, Иркутск, ул. Лермонтова, 83, Россия
}

Рассмотрено проявление электромагнитного (ЭМ) сигнала над проводящей поляризующейся Землёй на измерительных линиях, расположенных на оси источника и внутри него (для симметричной установки Шлюмберже).

Исследование основано на численном эксперименте. Проводились расчёты ЭМ отклика от одномерных моделей. Учёт поляризуемости реализован введением частотно зависимого удельного электрического сопротивления моделью Коула-Коула.

Описаны результаты численного эксперимента по расчёту сигнала становления над проводящей поляризующейся средой на 2-х и $3-x$ электродных заземлённых измерительных линиях, расположенных в осевой и экваториальной области источника заземлённая линия. Показано различие проявления индуктивного сигнала (становления поля) и сигнала вызванной поляризации, связанного с гальваническим и вихревым током.

Ключевые слова: электромагнитные зондирования, заземлённая линия, трёхэлектродная заземлённая измерительная линия, зондирования проводящих поляризующихся сред, модель Коула-Коула, индукционно вызванная поляризация, ВПИ, гальванически вызванная поляризация, ВПГ, прямая задача для проводящей поляризующейся среды.

\section{RESEARCH OF THE CONDUCTIVE POLARIZIABLE MEDIUM BY THE ARTIFICIAL PULSED ELECTROMAGNETIC SOURCE IS A GROUNDED ELECTRIC LINE}

\author{
E.V. Ageenkov, A.A. Sitnikov, I.Yu. Pesterev, A.V. Popkov
}

The manifestation of electromagnetic (EM) signal over the conducting polarizable Ground on the measuring lines located on the axis of the source and inside it (for the symmetric Schlumberger installation) is considered.

The research is based on a numerical experiment. Calculations of the EM response from one-dimensional models were carried out. The polarizability is taken into account by the frequency-dependent resistivity by the Cole-Cole model.

The results of numerical experiment on calculation of the signal of formation over the conducting polarizable medium on 2 and 3 electrode grounded measuring lines located in the axial and equatorial region of the source-the grounded line are described. Shows the difference of the manifestation of the inductive signal and the signal caused by the polarization associated with the galvanic and eddy current. 
Key words: electromagnetic sounding, grounded electrical line, tri-electrodes grounded received line, conductive polarizable medium sounding, Kole-Kole model, inductive induce polarization, IIP, galvanic induce polarization, GIP, forward modeling for conductive polarizable medium.

\section{ВВЕДЕНИЕ}

Геологическая среда с точки зрения современной геоэлектрики представляется многофазным гетерогенным образованием обладающим дисперсией электромагнитных (ЭМ) свойств. Ряд релаксационных процессов сопровождается возникновением ЭМ сигнала, который накладывается на индуктивный ЭМ сигнал становления поля (СП). Общий сигнал может быть зарегистрирован электроразведочными измерителями на поверхности или внутри среды.

Изучение ЭМ сигнала, связанного с релаксационными процессами, различными электроразведочными методами позволяет получить дополнительную информацию о свойствах геологической среды: пористости, влажности, степени сортировки частиц или о присутствии мёрзлых образований или примесей, воздействии УВ.

Искусственный импульсный источник ЭМ поля используется в электроразведке для возбуждения переходного процесса в геологической среде, сопровождающегося релаксационными процессами. Наиболее распространённые искусственные источники заземлённая электрическая линия и индуктивная (незаземлённая) петля, их воздействие на изучаемую среду различно. Заземлённая линия в импульсном режиме создаёт в проводящей среде гальванический и вихревой ток, петля воздействует только индуктивно, создавая вихревой ток. Эти токи порождают изменения в среде, которые при возвращении среды в первоначальное равновесное состояние сопровождаются ЭМ сигналами, характеризующими эти процессы. Соответственно для заземлённой линии будут возникать процессы ВП, связанные как с гальваническим, так и вихревым током, для петли будут возникать релаксационные процессы, связанные только с вихревым током. На измерителях будет проявляться общий сигнал.

Проявление сигнала ВП после импульсного воздействия для электрических линий, находящихся в осевой [Комаров, 1980] и экваториальной [Вишняков и др, 1988; Петров, 2000] области источника исследовалось неоднократно, однако не проводилось разделение какой ток порождает релаксационные процессы, гальванический и вихревой или той и другой природы.

Проявление сигнала индукционно вызванной поляризации (ВПИ) изучалось для индуктивной установки [Компаниец и др., 2012; Кожевников, 2014; Каменецкий и др., 2014; Халлбауэр-Задорожная, 2016 и др.], для заземлённых электрических линий этот вопрос исследовался меньше [Легейдо, 1998; Моисеев, 2002]. П.Ю. Легейдо предложил ряд геоэлектрических моделей, основанных на геологических условиях Юга Сибирской платформы, в которых ВП связана с гальваническим и вихревым током. Развивая эту тему, было проведено численное моделирование для осевой и симметричной электрических установок, в публикации описаны результаты моделирования и предложена интерпретация полученных результатов.

Более сложный переходный процесс от источника заземлённая линия требует более подробного рассмотрения. Становление и вызванная поляризация, связанная с гальваническим и вихревым током, по-разному проявляются на измерителях, 
размещённых в осевой и экваториальной области источника. Такие различия необходимо знать для правильного планирования натурных измерений и понимания их результатов.

ЭМ поле во время переходного процесса рассчитывалось на 2-х и 3-х электродных [Легейдо и др., 1995 и 1997] измерительных линиях. Для 2-х электродных линий рассчитывался сигнал переходного процесса, для 3-х электродных линий - сигнал переходного процесса, вторая конечная разность сигнала переходного процесса и трансформанта ЭМ поля - их отношение [Легейдо, 1995 и 1997]. Известно, что такое трансформирование сигналов, измеренных в осевой области источника, позволяет уменьшить проявление индукционной составляющей переходного процесса в поздней стадии становления. С этого момента поведение трансформанты определяется гальванически вызванной поляризацией. Описание проявления в трансформанте сигнала, связанного с индукционно вызванной поляризацией, ещё одна задача, которая стоит перед этим исследованием.

\section{ЗЕМЛЯ - МНОГОФАЗНАЯ ГЕТЕРОГЕННАЯ СРЕДА}

В геологической среде переменное ЭМ поле распространяется диффузионно, проникновение поля внутрь земли сопровождается возникновением вихревого тока и вторичного ЭМ поля. Течение вихревого тока вызывает ряд различных процессов разделения зарядов. Затухание вихревого тока, вследствие тепловых потерь, приводит к возникновению релаксационных процессов, проявляющихся как ЭМ сигнал.

Протекание гальванического тока в этой среде сопровождается аналогичными явлениями, в конечном итоге так же проявляющимися как ЭМ сигнал.

С точки зрения современной геоэлектрики геологическая среда представляется проводящим многофазным гетерогенным образованием, обладающим дисперсией ЭМ свойств. Которая вызвана протеканием ряда релаксационных процессов (инерционных процессов, характеризующихся временем релаксации) на границах фаз или внутри областей с контрастными изменениями ЭМ свойств.

Дисперсия ЭМ свойств, проявляющаяся в электроразведочных измерениях в разных диапазонах времени регистрации (или частотных диапазонах), в геоэлектрике имеют несколько обозначений: эффект вызванной поляризации (ВП) или низкочастной дисперсии (НЧД) [Каменецкий, 1997], релаксация Максвелла-Вагнера [Губатенко, 1991] и ориентационная поляризация, свойственная диэлектрикам [Аузин, Зацепин 2015]. Эти эффекты проявляются на времёнах от нс - ориентационная поляризация [Аузин, Зацепин, 2015], до сотен мс и с - ВП [Халлбауэр-Задорожная, 2016].

Для описываемого численного эксперимента учёт эффектов вызванной поляризации осуществлён введением частно-зависимого удельного электрического сопротивления (УЭС). Частотная дисперсия УЭС описывалась моделью Коула-Коула (1) [Могилатов, 2014]:

$$
\rho(\omega)=\rho_{0}\left(1-\frac{\eta(i \omega \tau)^{c}}{1+(i \omega \tau)^{c}}\right),
$$

где $\rho_{0}-$ удельное электрическое сопротивление на постоянном токе (Ом·м); $\eta$ коэффициент поляризуемости (доли ед.); $\tau$ - постоянная времени (с); $c$ - показатель степени; $\omega$ - круговая частота (сек $\left.{ }^{-1}\right)$. 


\section{ИНДУКЦИОННО ВЫЗВАННАЯ ПОЛЯРИЗАЦИЯ ПРИ ВОЗБУЖДЕНИИ ПЕРЕХОДНОГО ПРОЦЕССА ИНДУКТИВНЫМ ИСТОЧНИКОМ}

Первые исследования проявления сигнала ВП в электрометрических измерениях были связаны с заземлёнными электрическими линиями, главным образом, после воздействия гальванического тока на многофазную геологическую среду, регистрировались проявления электрохимических и электрокинетических процессов [Комаров, 1980; Жданов, 2012]. При измерениях индуктивными установками и импульсном возбуждении переходного процесса, отмечались немонотонные спады вплоть до смены полярности сигнала, которые невозможно было описать диффузионным распространением ЭМ поля в проводящей среде [Кожевников, 2012]. Первоначально объяснение этому эффекту было найдено на основе макроскопически гетерогенной среды, связано с проявлением эффекта Максвелла-Вагнера в мёрзлых породах с частотно независимыми удельной проводимостью $(\sigma)$ и диэлектрической проницаемостью $(\varepsilon)$ [Сидоров, 1987]. Затем было показано, что в ряде случаев, и в первую очередь, применительно к условиям криолитозоны аномальные переходные характеристики удаётся объяснить в рамках модели однородной геологической среды содержащей вещества с полярными молекулами, и теории диэлектрической релаксации Дебая [Кожевников, 2012; Кожевников и др. 2014].

ВПИ - возникает при воздействии на поляризующуюся среду вихревого тока (рис. 1a). Её проявление в ЭМ сигнале хорошо видно при индукционном возбуждении и приёме поля становления (во временной области). В результатах измерений ЗСБ с соосными установками ВПИ проявляется как сигнал противоположного знака в отличие от становления ЭМ поля. ВПИ может быть связана с рядом релаксационных процессов различной природы. Наиболее быстропротекающая релаксация наблюдается в мёрзлых породах. Она проявляется на временах от первых мкс до первых мс. Более инерционны процессы электрокинетической и электролитической природы. Электрокинетические процессы - электроосмос и мембранная поляризация, связанные с двойным электрическим слоем (ДЭС) двухфазной пористой среды и изменениями диаметров пор. Длительность электроосмической релаксации от первых мс до сотен мс. Мембранная поляризация устанавливается от мс до с [Халлбауэр-Задорожная, 2016]. Электролитические процессы связаны с присутствием электронно-проводящих включений внутри пористой (трещиноватой) геологической среды. Они длятся от первых мс до с.

Рис. 1. Структура вихревых токов: а). для источника индуктивная петля; б). для источника заземлённая линия.

Проявление электрофизической релаксации в индуктивных измерениях называют быстропротекающая индукционно вызванная поляризация (БВПИ) [Кожевников, 2012]. Есть данные о быстропротекающей вызванной поляризации (БВП) в измерениях с заземлёнными линиями [Карасёв и др., 2005]. Проявление электрокинетической и электролитической релаксации называют низкочастотная дисперсия (НЧД) или вызванная поляризация (ВП) [Каменецкий, 1997].

Для индукционного возбуждения и приёма неустановившегося ЭМ поля характерно возбуждение только вихревых токов, которые протекая в поляризующейся среде возбуждают ВПИ, связанную с релаксационными процессами различной природы. Но плотность вихревых токов меньше, чем гальванических и время их протекания в Земле 
меньше, чем гальванических, поэтому для изучения ВП такая система возбуждения и приёма применяется редко. Можно утверждать, что процессы ВПИ, как правило, являются мешающими для изучения процесса становления индуктивными установками.

При индуктивном возбуждении и приёме ЭМ сигнала переходного процесса поляризация, вызванная вихревым током - индукционно вызванная поляризация (ВПИ), проявляется в смене знака ЭДС.

\section{ПЕРЕХОДНЫЙ ПРОЦЕСС В ПРОВОДЯЩЕЙ ПОЛЯРИЗУЮЩЕЙСЯ СРЕДЕ ПРИ ВОЗДЕЙСТВИИ НА НЕЁ ИМПУЛЬСНОГО ИСТОЧНИКА - ЗАЗЕМЛЁННОЙ ЭЛЕКТРИЧЕСКОЙ ЛИНИИ}

Заземлённая электрическая линия воздействует на проводящую поляризующуюся среду несколько по-другому нежели индуктивный источник [Могилатов, 2014]. При подаче разности потенциалов на питающие электроды в среде устанавливается потенциальное ЭМ поле, вызывающее течение гальванического тока. Распределение плотности тока в среде зависит от её проводимости и размеров источника и убывает с глубиной и при горизонтальном удалении от источника. Появление гальванического тока приводит к разделению зарядов в геологической среде, длящееся определяемое время. Появляется поле ВП противодействующее потенциальному полю заземлённого источника. Это проявляется в изменяющейся разности потенциалов на измерителе во время токового импульса после включения тока и в осевой и в экваториальной области источника. Разность потенциалов растёт и, при достаточной продолжительности импульса, может достигнуть асимптоты - разности потенциалов на постоянном токе.

Во время импульса тока в нижнем полупространстве ток течёт от электрода А к электроду В (для импульсов одной полярности), в кабеле источника от электрода В к электроду А, замыкая токовое кольцо. Силовые линии постоянного магнитного поля, образующие магнитный поток $\Phi_{1}$, охватывают токовые линии. Ток I, текущий в кабеле, растекается в нижнем полупространстве с неравномерной плотностью. В экваториальной области источника, она начинает резко уменьшаться на глубине приблизительно AB/2 [Матвеев, 1990]. В осевой области источника плотность тока убывает с увеличением разноса, но глубина до которой плотность тока практически не уменьшается возрастает с увеличением разноса. Так называемая эффективная глубина зондирования на постоянном токе в осевой области источника сопоставима с разносом [Матвеев, 1990].

После выключения питающего тока в среде начинаются изменения токов и ЭМ поля. Меняется направление поля ВП, теперь оно направлено так же, как и первичное потенциальное поле источника. Разделённые, под воздействием внешнего тока, заряды начинают возвращаться в первоначальное положение, начинает течь ток гальванически вызванной поляризации, сопровождающийся возникновением ЭМ сигнала. Это процесс инерционный, а точнее, ряд процессов различной природы, каждый из которых характеризуется временем релаксации, поэтому разность потенциалов на измерителях после выключения тока исчезает не сразу, а наблюдается спад ВП [Комаров, 1980].

Одновременно с выключением первичного тока в проводящей среде начинается индуктивный процесс диффузии вихревого тока. После выключения гальванического тока, текущего в проводе и в земле, начинает уменьшаться магнитный поток $\Phi_{1}$, пронизывающий этот контур. Благодаря явлению самоиндукции образуется магнитный поток $\Phi_{2}$, препятствующий уменьшению потока $\Phi_{1}$, направлен он в ту же сторону, что и 
первичный поток. Поток $\Phi_{2}$ индуцирует вихревой ток, его пространственное распределение повторяет структуру гальванического тока везде кроме экваториальной области источника, под кабелем, соединяющим электроды А и В, образуется область с противоположным направлением движения тока высокой плотности, создавая ток эквивалентный току в кабеле в момент импульса и замыкающий кольцо вихревого тока. На симметричном измерителе разность потенциалов меняет свой знак на противоположный относительно разности потенциалов во время пропускания. Знак $\Delta \mathrm{U}(\mathrm{t})$ на измерителе в осевой области источника не изменяется.

Первоначально вихревой ток, главным образом в области, где его плотность максимальна, удерживается в соленоидальной ловушке высокочастотным магнитным полем, которое препятствует его растеканию и проникновению вглубь [Матвеев, 1990] это ранняя стадия переходного процесса (РСПП) (рис. 2а). Когда магнитное поле ослабевает ток начинает просачиваться (диффундировать) внутрь проводящей среды (вглубь и вширь) - проходит процесс становления ЭМ поля (СП) (рис. 2б). Вихревой ток стремится к равномерной плотности в среде (рис. 2в).

Рис. 2. Изолинии плотности вихревого тока в разные моменты переходного процесса (По Strack, 1992).

Для наглядного представления изменения структуры вихревого тока для индуктивного и гальванического источника показано кольцо максимальной плотности вихревого тока для двух моментов времени переходного процесса (Рис. 1). Кольцо вихревых токов для источника заземлённая линия растекается вглубь преимущественно в плоскости перпендикулярной поверхности земли [Strack, 1992], кольца вихревых токов, созданного индуктивной петлёй, диффундирует вглубь проводящей среды в плоскости параллельной земной поверхности [Nabighian, 1979].

Возникающий вихревой ток, так же приводит к разделению зарядов в гетерогенной многофазной геологической среде, а когда он затухает, вследствие тепловых потерь, среда вновь будет инерционно возвращаться в первоначальное равновесное состояние, сопровождая это течением тока индукционно вызванной поляризации и образованием ЭМ сигнала.

Т.о. заземлённая линия в импульсном режиме в проводящей поляризующейся среде порождает ток гальванически вызванной поляризации - при включённом источнике, вихревой ток и ток индукционно вызванной поляризации - после выключения источника, течение которых сопровождается возникновением ЭМ сигнала, регистрируемого на поверхности измерителями. Индукционная составляющая сигнала связана со вторичным ЭМ полем вихревого тока, текущего в проводящих областях геологической среды. Сигнал гальванически вызванной поляризации связан с релаксационными процессами, вызванными гальваническим током. Сигнал индукционно вызванной поляризации связан с релаксационными процессами, вызванными вихревым током.

\section{ИЗМЕРИТЕЛИ - ЗАЗЕМЛЁННЫЕ ЛИНИИ И З-Х ЭЛЕКТРОДНЫЕ ЗАЗЕМЛЁННЫЕ ЛИНИИ}

Трёхэлектродные измерительные линии ( $\left.\mathrm{M}_{1} \mathrm{M}_{2} \mathrm{M}_{3}, \mathrm{M}_{2} \mathrm{M}_{3} \mathrm{M}_{4}, \mathrm{M}_{3} \mathrm{M}_{4} \mathrm{M}_{5}, \mathrm{M}_{4} \mathrm{M}_{5} \mathrm{M}_{6}\right)$ позволяют измерять сигнал переходного процесса между электродами $\mathrm{M}_{1}-\mathrm{M}_{3} \mathrm{M}_{2}-\mathrm{M}_{4} \mathrm{M}_{3}-\mathrm{M}_{5}$ 
$\mathrm{M}_{4}-\mathrm{M}_{6}$ и вторую конечную разность этого сигнала на трёх электродах, затем формировать ряд трансформант ЭМ поля, позволяющих подавить вклад электродинамической составляющей в поздней стадии переходного процесса и усилить вклад гальванически вызванной поляризационной составляющей. На основе расчётного сигнала переходного процесса между электродами $\mathrm{M}_{1}-\mathrm{M}_{2}, \mathrm{M}_{2}-\mathrm{M}_{3}, \mathrm{M}_{3}-\mathrm{M}_{4}, \mathrm{M}_{4}-\mathrm{M}_{5}, \mathrm{M}_{5}-\mathrm{M}_{6}$ можно сформировать разность потенциалов $\Delta U$ между крайними электродами каждой трёхэлектродной измерительной линии (2), например, для линии $\mathrm{M}_{1} \mathrm{M}_{2} \mathrm{M}_{3}$, и вторую конечную разность сигнала переходного процесса $\Delta^{2} U$ (3). Затем рассчитать трансформанту, названную Р1, как отношение $\Delta^{2} U$ к $\Delta U$ (4) [Легейдо, Мандельбаум, Рыхлинский 1995, 1997; Легейдо, 1998].

$$
\begin{gathered}
\Delta U_{M_{1} M_{3}}=\Delta U_{M_{1} M_{2}}+\Delta U_{M_{2} M_{3}} \\
\Delta^{2} U_{M_{1} M_{2} M_{3}}=\Delta U_{M_{1} M_{2}}-\Delta U_{M_{2} M_{3}} \\
P 1_{M_{1} M_{2} M_{3}}=\frac{\Delta^{2} U_{M_{1} M_{2} M_{3}}}{\Delta U_{M_{1} M_{3}}}=\frac{\Delta U_{M_{1} M_{2}}-\Delta U_{M_{2} M_{3}}}{\Delta U_{M_{1} M_{2}}+\Delta U_{M_{2} M_{3}}}
\end{gathered}
$$

В такой трансформации составляющая ЭМ поля стремящаяся к однородности в пространстве будет уменьшаться, а неоднородная в пространстве, напротив, будет приобретать больший вес (подчёркиваться).

\section{ПРОЯВЛЕНИЕ СИГНАЛА ВП, СВЯЗАННОГО С ГАЛЬВАНИЧЕСКИМ И ВИХРЕВЫМ ТОКОМ, НА ЛИНИЯХ, РАСПОЛОЖЕННЫХ В ОСЕВОЙ И ЭКВАТОРИАЛЬНОЙ ОБЛАСТИ ИСТОЧНИКА}

Для электрических установок, в режиме постоянного тока и импульсного возбуждения, распространены установки с измерителями в осевой или экваториальной области источника. Установки с измерениями в осевой области часто называют дипольными, хотя разнос является небольшим и не позволяет пренебречь истинными размерами линий. Установки с измерителем в экваториальной области зачастую являются симметричными относительно центра источника.

Эффективная глубина зондирования на постоянном токе оценивается по расстоянию между источником и измерителем, для измерений в осевой области источника, и по размеру питающей линии, для измерений симметричной установкой.

Постоянный ток, созданный в среде заземлённой электрической линией, растекается в нижнем полупространстве неравномерно, наибольшую плотность оценивают до глубины сопоставимой с длиной разноса - для измерений в осевой области источника или до половины длины источника - для измерений симметричной установкой.

Для источника заземлённая линия известно, что измеряемый сигнал электродинамического переходного процесса и ВПГ для одномерной среды в осевой зоне источника имеют одинаковый знак, а в экваториальной зоне - разный [Вишняков и др., 1988; Петров, 2000; Моисеев, 2002; Антонов, Шеин, 2006].

Расчёты проведём для электрической установки с измерением в осевой и экваториальной области источника (рис. 3), состоящей из источника $\mathrm{AB}$, нескольких измерительных линий $\mathrm{M}_{1} \mathrm{M}_{2}, \mathrm{M}_{2} \mathrm{M}_{3}, \mathrm{M}_{3} \mathrm{M}_{4}, \mathrm{M}_{4} \mathrm{M}_{5}, \mathrm{M}_{5} \mathrm{M}_{6}$, расположенных в осевой области источника и измерительной линии $\mathrm{MN}$, расположенной в экваториальной области 
источника. Расстояние между центром питающей и измерительных линий: 1500, 2500, 3500, 4500 и 5500 м. Временной диапазон изучения сигнала ограничим от 100 мкс до 2 с.

Для такой установки эффективная глубина зондирования на постоянном токе будет увеличиваться для измерений в осевой области с 300 до 1100 м. Для симметричной линии длиной 400 м при длине источника 1000 м, она составит приблизительно 500 м.

Гальванический ток, растекаясь в земле с двух заземлений, создаёт потенциальное ЭМ поле, которое, в частности, в осевой области источника уменьшается при удалении от него. Токи вызванной поляризации, которые повторяют распределение в земле токов, вызвавших их, и ЭМ поле, созданное токами ВПГ, также будут сохранять неоднородность в осевой области источника.

Рис. 3. Схема установки численного эксперимента. Измерительные линии в осевой $\left(\mathrm{M}_{1} \mathrm{M}_{2}\right.$, $\mathrm{M}_{2} \mathrm{M}_{3}, \mathrm{M}_{3} \mathrm{M}_{4}, \mathrm{M}_{4} \mathrm{M}_{5}, \mathrm{M}_{5} \mathrm{M}_{6}$ ) и экваториальной (MN) области источника (AB).

При импульсном возбуждении, после изменения тока источника, в проводящей среде возникает вихревой ток. Для рассматриваемого источника в начале переходного процесса структура вихревого тока будет повторять структуру гальванического тока (рис. 1б). Переходный процесс связан с растеканием кольца основной плотности вихревых токов вниз и вширь (рис. 2), так что в поздней стадии его плотность равномерно распределяется в нижнем полупространстве, что проявится в уменьшении пространственной неоднородности индуктивного ЭМ поля, которая в поздней стадии переходного процесса будет близка к нулю. Для наглядного представления изменения структуры вихревого тока для индуктивного и гальванического источника показано кольцо максимальной плотности вихревого тока для двух моментов времени переходного процесса. Кольцо вихревых токов для источника заземлённая линия растекается вглубь преимущественно в плоскости перпендикулярной поверхности земли [Strack, 1992], кольца вихревых токов, созданного индуктивной петлёй, диффундирует вглубь проводящей среды в плоскости параллельной земной поверхности [Nabighian, 1979].

Вихревой ток, диффундируя в проводящей среде, становится источником разделения зарядов. После его затухания заряды возвращаются в первоначальное положение, образуя ток индукционно вызванной поляризации.

Становление поля, поляризация вызванная, как гальванически, так и индукционно, протекают совместно и проявляются как общий ЭМ сигнал на измерителях. Однако пространственное распределение плотности этих токов и её изменение во время переходного процесса будет различаться, что даёт надежду выделить составляющие из общего измеренного (рассчитанного) сигнала.

Легейдо [Легейдо, 1998] предложил ряд геоэлектрических моделей, основанных на геологических условиях Юга Сибирской платформы (табл. 1-4), в которых ВП связано преимущественно с гальваническим током («ВПГ»), преимущественно с вихревым током («ВПИ»), с двумя типами тока («ВПГ и ВПИ») и модель в которой ВП не образуется («Без ВП»). 4-слойный горизонтально-слоистый разрез типа КН, первый и третий, относительно проводящие, слои разделены высокоомным экраном. В основании разреза лежит непроводящий фундамент. Можно предположить, что отклик ВП от первого слоя создаётся гальваническим и вихревым током, расположенный ниже экрана проводящий 
поляризующейся слой, предположительно будет возбуждаться, индуктивно и поляризационный отклик будет индукционным.

Поляризационные характеристики первого и третьего слоя значительно различаются. Для первого слоя поляризуемость равна 2\%, для третьего - 50\%. Такое, на первый взгляд, завышенное значение поляризуемости третьего слоя используется для увеличения эффекта ВП, связанного с ним. В предположении, что поляризационный эффект от этого слоя будет значительно слабее, а возможно и совсем не проявится на фоне сигнала ВП, связанного с первым слоем, чтобы различить поляризационные составляющие, вызванные гальваническим и вихревым током, необходимо было придать резко отличающие ЭМ свойства подэкранной толще. Описываемое исследование можно считать предваряющим исследования поляризационного отклика от геологических моделей на акваториях, когда поляризующиеся геологические слои перекрыты неполяризующейся водной толщей и эффект ВП связан только с ними. При большой мощности водной толщи и расположении источника и измерителя в верхних слоях воды гальваническое воздействие заземлённого источника на геологические слои может быть незначительным, тогда знание о проявлении индукционно вызванной поляризации в измеряемом сигнале позволит правильно интерпретировать результаты измерений.

Для изучения проявления ВПГ и ВПИ проведём сравнение сигналов над неполяризующейся средой, поляризующейся выше высокоомного второго слоя, поляризующейся ниже этого слоя и поляризующейся и выше и ниже него. Условно назовём эти модели: «Без ВП», «ВПГ», «ВПИ» и «ВПГ и ВПИ», соответственно.

Табл. 1

Модель «Без ВП» (из диссертации П.Ю. Легейдо)

Табл. 2

Модель «ВПГ» (из диссертации П.Ю. Легейдо)

Табл. 3

Модель «ВПГ и ВПИ» (из диссертации П.Ю. Легейдо)

Табл. 4

Модель «ВПИ» (из диссертации П.Ю. Легейдо)

Для всех моделей первоначально покажем на графиках расчёты абсолютных значений (модуля) сигнала переходного процесса для линий $\mathrm{M}_{1} \mathrm{M}_{2}, \mathrm{M}_{2} \mathrm{M}_{3}, \mathrm{M}_{3} \mathrm{M}_{4}, \mathrm{M}_{4} \mathrm{M}_{5}$, $\mathrm{M}_{5} \mathrm{M}_{6}$ (рис. 4) и симметричной линии $\mathrm{MN}$ (рис. 5).

Для соосных измерителей первоначально после выключения импульса выполняется условие волновой зоны. На них регистрируется отклик сигнала, распространившегося по воздуху как ЭМ волна и возбудившего в земле неустановившееся поле. Этот сигнал слабо изменяется - наблюдается асимптотическая ветвь на ранних временах, в нашем случае, на интервале времени со 100 мкс до 1 мс. Такое поведение сигнала свидетельствует о РСПП. Уровень асимптоты зависит от разноса. Над неполяризующейся Землёй (пунктирная линия на графиках), после асимптоты РСПП наблюдается одинаковый монотонный спад сигнала становления поля на линиях $\mathrm{M}_{1} \mathrm{M}_{2}, \mathrm{M}_{2} \mathrm{M}_{3}, \mathrm{M}_{3} \mathrm{M}_{4}, \mathrm{M}_{4} \mathrm{M}_{5}, \mathrm{M}_{5} \mathrm{M}_{6}$ (рис. 4a). Со времени примерно 30 мс сигналы на всех измерительных линиях становятся практически равными - исчезает зависимость от разноса, это свидетельствует о равномерном распределении 
вихревых токов в Земле. Этим характеризуется поздняя стадия становления ЭМ поля в среде.

На линии MN сигнал становления поля имеет противоположный знак относительно первичного поля.

Над землёй, поляризующейся в верхней части разреза (рис. 4б, сплошные линии на графиках), на линиях $\mathrm{M}_{1} \mathrm{M}_{2}, \mathrm{M}_{2} \mathrm{M}_{3}, \mathrm{M}_{3} \mathrm{M}_{4}, \mathrm{M}_{4} \mathrm{M}_{5}, \mathrm{M}_{5} \mathrm{M}_{6}$ спад отличается от спада над неполяризующимся разрезом и различие сигнала переходного процесса на них сохраняется на протяжении всего времени расчётов. На симметричной линии MN сигнал меняет знак (переходит из отрицательной области в положительную) со времени около 10 мс - так проявляется сигнал ВПГ.

При преобладании ВПИ (рис. 4г, красные линии крупным пунктиром с точкой) переходный процесс на линиях $\mathrm{M}_{1} \mathrm{M}_{2}, \mathrm{M}_{2} \mathrm{M}_{3}, \mathrm{M}_{3} \mathrm{M}_{4}, \mathrm{M}_{4} \mathrm{M}_{5}, \mathrm{M}_{5} \mathrm{M}_{6}$ значительно отличается. Сигнал на ближних измерительных линиях $\left(\mathrm{M}_{1} \mathrm{M}_{2}\right.$ и $\left.\mathrm{M}_{2} \mathrm{M}_{3}\right)$ после времени около 30 мс становится меньше, чем на более удалённых от источника линиях $\left(\mathrm{M}_{3} \mathrm{M}_{4}, \mathrm{M}_{4} \mathrm{M}_{5}, \mathrm{M}_{5} \mathrm{M}_{6}\right)$, их различие с течением времени увеличивается, после времени 70 мс $\Delta \mathrm{U}_{\mathrm{M} 1 \mathrm{M} 2}$ и после времени 300 мс $\Delta \mathrm{U}_{\mathrm{M} 2 \mathrm{M} 3}$ становятся отрицательными. На симметричной линии происходит смена знака сигнала, аналогичная случаю с предыдущей моделью, только время перехода через ноль увеличивается и происходит на 30 мс, можно констатировать, что так проявляется сигнал ВП связанный с гальваническим током.

Увеличение эффективной глубины зондирования постоянным током дипольной установкой приводит к увеличению в регистрируемом сигнале доли вызванной поляризации, связанной с гальваническим током. Для измерителей, более удалённых от источника смена знака сигнала переходного процесса не происходит. На малых расстояниях поляризационный отклик гальванически возбуждённой среды будет доходить с небольших глубин (в соответствии с оценкой глубинности проникновения постоянного тока для дипольной установки), а поляризационный сигнал, связанный с вихревым током, будет идти с больших глубин, при увеличении разноса отклик гальванически вызванной поляризации будет регистрироваться с больших глубин и индукционно вызванная поляризация не будет проявляться во временном диапазоне используемом для расчётов.

Над моделью с совместным проявлением ВПГ и ВПИ (рис. 4в, линии крупным пунктиром) сигнал переходного процесса на второй измерительной линии на времени порядка 100 мс становится меньше, чем на ближней и более удалённых измерительных линиях. С течением времени различие $\Delta \mathrm{U}_{\mathrm{M} 2 \mathrm{M} 3}$ и $\Delta \mathrm{U}$ на других линиях увеличивается, но смены знака разности потенциалов, до времени окончания измерений - 2 с, ни на второй, ни на других измерителях не отмечается. На симметричной линии смена знака сигнала происходит незначительно раньше, чем над моделью «ВПГ». Можно предположить, что незначительное увеличение временного диапазона преобладания сигнала ВП на индукционной составляющей связано с совместным влиянием двух поляризующихся слоёв - наблюдается эффект наложения сигналов гальванически и индукционно вызванной поляризации - общий отклик.

Рис. 4. Абсолютные значения сигнала переходного процесса на измерительных линиях, имеющих разнос 1500, 2500, 3500, 4500, 5500 м: а). Над неполяризующейся средой; б). Над средой, поляризующейся в верхней части разреза; в). Над поляризующейся средой; г). Над средой, поляризующейся под высокоомным экраном. 
Для другого представления данных можно объединить модули сигналов от всех моделей для каждой измерительной линии (рис. 6). Графики приведены в одном билогарифмическом масштабе. На них видны различия сигналов над неполяризующейся средой (пунктирная линия), над средой, поляризующейся в верхней части (сплошные линии), над средой, поляризующейся и в верхней части и под высокоомным экраном (линии широким пунктиром) и над средой, поляризующейся только под высокоомным экраном (красные линии широким пунктиром с точкой). Различия сигналов, изменяются в зависимости от разноса, их удобно рассматривать на фоне сигнала от неполяризующейся среды, который после времени 50 мс одинаков на всех разносах. Для самого ближнего разноса - 1500 м сигнал для поляризующейся под высокоомным экраном среды значительно отличается от других сигналов. Он переходит через ноль на времени 70-80 мс и приобретает отрицательные значения, поэтому сигнал над «ВПГ» больше чем над «ВПГ и ВПИ». Общий сигнал над «ВПГ и ВПИ» уменьшается за счёт отрицательных значений индукционно вызванной поляризации.

Рис. 5. Абсолютные значения сигнала становления на симметричной измерительной линии: а). Над неполяризующейся средой; б). Над средой поляризующейся в верхней части разреза; в). Над поляризующейся средой; г). Над средой поляризующейся под высокоомным экраном.

Для разноса 2500 м картина сохраняется, только отрицательные значения ВПИ становятся на порядок меньше по амплитуде и переход через 0 наблюдается позднее - на времени 300-400 мс. Меньше и различие сигналов «ВПГ» и «ВПГ и ВПИ».

При разносе 3500 м происходит кардинальное перераспределение откликов. Сигнал от модели, поляризующейся под экраном не меняет знак на протяжении всего времени расчётов. Сигнал от модели «ВПГ» после 30 мс становится меньше сигналов от моделей «ВПИ» и «ВПГ и ВПИ».

Для разноса 4500 м амплитуда сигнала от модели «ВПГ» уменьшается, по сравнению с предыдущим разносом, а сигнал от модели «ВПИ» приближается к сигналу от модели «ВПГ и ВПИ».

При удалении измерителя от источника на 5500 м сигнал от модели «ВПГ» практически сливается с сигналом от неполяризующейся среды, то же происходит и с откликами от моделей «ВПИ» и «ВПГ и ВПИ».

Для симметричной установки с самых ранних времён наблюдается спад сигнала. По интерпретации Б.К. Матвеева [Матвеев, 1990] для индуктивного источника и приёмника если измеритель находится вне кольца максимальной плотности вихревых токов, то он находится в условиях Д3, если оказывается внутри этого кольца, регистратор сигнала оказывается в условиях Б3. Для заземлённой линии ситуация аналогичная и для симметричного измерителя всё время выполняется условие БЗ.

Во время переходного процесса на симметричном измерителе для всех поляризующихся моделей присутствует смена знака сигнала. Сигнал СП имеет противоположный знак относительно возбуждающего импульса, для поляризующихся моделей он меняет знак по мере затухания индукционного процесса. 
Рис. 6. Абсолютные значения сигнала переходного процесса от 4-х моделей на измерительных линиях, удалённых на: а). 1500; б). 2500; в). 3500; г). 4500; д). 5500 м.

На графиках (рис. 7) для каждой 3-х электродной измерительной установки приведены абсолютные значения амплитуды сигнала переходного процесса между её крайними электродами от четырёх моделей.

Отклик от неполяризующейся модели (пунктирная линия) на поздних временах одинаков для всех линий и сигналы от других моделей удобно рассматривать относительно этой кривой.

Смена знака сигнала отмечается только от модели «ВПИ» для ближней линии ( $\mathrm{M}_{1-}$ $\mathrm{M}_{3}$ ). При увеличении разноса отклик «ВПИ» на поздних временах положительный и по амплитуде становится больше, чем для первого разноса.

Амплитуда сигнала «ВПГ» при увеличении разноса в поздней стадии уменьшается и приближается к сигналу «Без ВП».

Сигнал «ВПГ и ВПИ» (широкий пунктир) на всех разносах положительный и по мере увеличения разноса и уменьшения амплитуды сигнала от «ВПГ» в поздней стадии переходного процесса к нему стремится сигнал от «ВПИ».

Рис. 7. Абсолютные значения сигнала переходного процесса на 3-х электродных измерительных линиях $\mathrm{M}_{1} \mathrm{M}_{2} \mathrm{M}_{3}, \mathrm{M}_{2} \mathrm{M}_{3} \mathrm{M}_{4}, \mathrm{M}_{3} \mathrm{M}_{4} \mathrm{M}_{5}, \mathrm{M}_{4} \mathrm{M}_{5} \mathrm{M}_{6}$.

Близость значений разности потенциалов на смежных линиях $\mathrm{M}_{1} \mathrm{M}_{2}, \mathrm{M}_{2} \mathrm{M}_{3}, \mathrm{M}_{3} \mathrm{M}_{4}$, $\mathrm{M}_{4} \mathrm{M}_{5}, \mathrm{M}_{5} \mathrm{M}_{6}$ показывает вторая конечная разность сигнала переходного процесса $\left(\Delta^{2} \mathrm{U}(\mathrm{t})\right)$ (рис. 8). На симметричной установке эта величина не формируется, т.к. для одномерной модели она равна нулю. Для неполяризующейся земли (пунктирная линия) на всех 3-х электродных измерительных линиях после 30 мс этот параметр резко уменьшается и после 200 мс его значения становятся меньше $1 \mathrm{e}^{-8}$ мВ/А (они не показаны на рис. 8).

Для модели «ВПИ» (широкий пунктир с точкой) отмечается смена знака сигнала $\Delta^{2} \mathrm{U}$ для линий $\mathrm{M}_{1} \mathrm{M}_{2} \mathrm{M}_{3}, \mathrm{M}_{2} \mathrm{M}_{3} \mathrm{M}_{4}, \mathrm{M}_{3} \mathrm{M}_{4} \mathrm{M}_{5}$. C увеличением разноса от первой линии до третьей отрицательные значения «ВПИ» по амплитуде становятся больше значений «ВПГ».

Для модели «ВПГ и ВПИ» (широкий пунктир) присутствует смена знака сигнала на линиях $\mathrm{M}_{2} \mathrm{M}_{3} \mathrm{M}_{4}$ и $\mathrm{M}_{3} \mathrm{M}_{4} \mathrm{M}_{5}$.

Для модели «ВПГ» (сплошная линия) смены знака сигнала на всех разносах не происходит, в время смены скорости спада увеличивается при удалении измерительной линии от источника.

Значительные изменения претерпевает сигнал $\Delta^{2} U$ для самой удалённой линии $\left(\mathrm{M}_{4} \mathrm{M}_{5} \mathrm{M}_{6}\right)$. На ней изменение сигнал в поздней стадии переходного процесса от моделей «ВПГ», «ВПГ и ВПИ» и «ВПИ» - схожи.

Рис. 8. Абсолютные значения второй конечной разности сигнала переходного процесса на 3-х электродных измерительных линиях $\mathrm{M}_{1} \mathrm{M}_{2} \mathrm{M}_{3}, \mathrm{M}_{2} \mathrm{M}_{3} \mathrm{M}_{4}, \mathrm{M}_{3} \mathrm{M}_{4} \mathrm{M}_{5}, \mathrm{M}_{4} \mathrm{M}_{5} \mathrm{M}_{6}$. 
На графиках (рис. 9) для каждой 3-х электродной измерительной линии в осевой области источника показана трансформанта P1 для четырёх моделей.

Трансформанта от неполяризующейся модели (пунктирная линия) после 100 мс выходит на 0 на всех разносах, что свидетельствует о стремлении к $0 \Delta^{2} U$.

P1 для модели «ВПГ» (сплошные линии) после изменения скорости спада параметра $\Delta^{2} U$ начинает возрастать и имеет восходящую правую ветвь на всех разносах. Начало восходящей ветви также смещается на более поздние времена при увеличении разноса.

Над моделью «ВПИ» (линии широким пунктиром с точкой) после времени смены знака второй конечной разности потенциалов на трёх первых линиях $\left(\mathrm{M}_{1} \mathrm{M}_{2} \mathrm{M}_{3}, \mathrm{M}_{2} \mathrm{M}_{3} \mathrm{M}_{4}\right.$, $\mathrm{M}_{3} \mathrm{M}_{4} \mathrm{M}_{5}$ ) можно наблюдать смену знака трансформанты Р1, которая имеет нисходящую правую ветвь отрицательных значений.

Над моделью с совместным проявлением ВПГ и ВПИ (линии крупным пунктиром) смена знака Р1 отмечается для второй и третьей линии.

Рис. 9. Переходная характеристика трансформанты Р1 на 3-х электродных измерительных линиях $\mathrm{M}_{1} \mathrm{M}_{2} \mathrm{M}_{3}, \mathrm{M}_{2} \mathrm{M}_{3} \mathrm{M}_{4}, \mathrm{M}_{3} \mathrm{M}_{4} \mathrm{M}_{5}, \mathrm{M}_{4} \mathrm{M}_{5} \mathrm{M}_{6}$.

\section{ИНТЕРПРЕТАЦИЯ ПОВЕДЕНИЯ РАЗНОСТИ ПОТЕНЦИАЛОВ НА ЗАЗЕМЛЁННЫХ ЛИНИЯХ И З-Х ЭЛЕКТРОДНЫХ ЗАЗЕМЛЁННЫХ ИЗМЕРИТЕЛЬНЫХ ЛИНИЯХ - ПРОЯВЛЕНИЕ ИНДУКЦИОННОГО ПРОЦЕССА, ВПГ И ВПИ}

Проведённые расчёты и различные визуальные представления сигнала от моделей с разной глубиной расположения поляризующихся объектов выполнены для того, чтобы, проанализировав их можно было понять, как сочетаются ЭМ сигналы разного происхождения в общем сигнале переходного процесса при импульсном режиме заземлённой электрической линии.

Для ближней измерительной линии $\left(\mathrm{M}_{1}-\mathrm{M}_{3}\right)$ сигнал переходного процесса меняет знак для модели «ВПИ», а при удалении измерительной линии знак сигнала $\Delta \mathrm{U}(\mathrm{t})$ не меняется - всегда положительный, так же, при увеличении разноса, увеличивается амплитуда отклика от модели «ВПИ». Для третьей линии $\left(\mathrm{M}_{3}-\mathrm{M}_{5}\right)$ сигнал «ВПИ» превосходит сигнал «ВПГ» и становится близок к сигналу «ВПГ и ВПИ». Такое поведение сигнала можно интерпретировать так, что гальванические токи, несмотря на мощный высокоомный экран, проникают через него и возбуждают подэкранную поляризующуюся толщу. При увеличении разноса увеличивается доля регистрируемого сигнала связанного с гальванически вызванной поляризации от подэкранной толщи, находящейся на глубине от 700 до 900 м. Эффективная глубина регистрации отклика гальванического тока, при условии 1/5 длины разноса, для осевых измерителей $\mathrm{M}_{1}-\mathrm{M}_{3}, \mathrm{M}_{2}-\mathrm{M}_{4}, \mathrm{M}_{3}-\mathrm{M}_{5}, \mathrm{M}_{4}-\mathrm{M}_{6}$ составляет приблизительно 400, 600, 800 и 1000 м. Нужно ещё раз отметить, что название моделей «ВПГ», «ВПИ» и «ВПГ и ВПИ» носит условный характер и описываемое поведение сигнала это наглядно демонстрирует.

Смену знака сигнала переходного процесса на линиях, расположенных в осевой области источника, можно связать с проявлением индукционно вызванной поляризации (рис. 10).

Рис. 10. Схематичное протекание переходного процесса над проводящей поляризующейся средой в осевой области источника на малых разносах. ИТ - пропускание 
тока; УВЗ - измерение переходного процесса в условиях волновой зоны; СП - становление поля; ВПГ - гальванически вызванная поляризация; ВПИ - индукционно вызванная поляризация; $\mathrm{t}_{0}$ - время выключения тока; $\mathrm{t}_{1}$ - время смены знака поля при проявлении ВПИ; $\mathrm{t}_{3}$ - время окончания измерений.

После импульса тока (ИТ) на измерительных линиях в осевой области источника регистрируется сигнал переходного процесса, связанный с импульсным возбуждением, распространившимся по воздуху (УВЗ), убывающий при удалении от источника зависящий от геометрии установки. Во время ранней стадии переходного процесса, когда появившийся вихревой ток поддерживает структуру исчезающего гальванического тока, сигнал переходного процесса на измерителях не уменьшается, это говорит о том, что плотность вихревого тока на этой стадии переходного процесса не изменяется какое-то время. После того как высокочастотное магнитное поле, удерживающее вихревой ток в соленоидальной петле, затухает [Матвеев, 1990] начинается диффузионное просачивание (растекание вглубь и вширь) в среде вихревого тока, плотность которого уменьшается, это отражается на уменьшении сигнала на измерителях во временном диапазоне СП. Как только вихревые токи затухают (их плотность становится меньше плотности токов гальванически и индукционно вызванной поляризации) сигнал начинает определяться токами ВПГ или ВПИ. Скорость диффузии вихревых токов (скорость протекания процесса СП) зависит от проводящих свойств геологической среды, соответственно момент, когда токи ВП начнут определять протекание переходного процесса, так же связано с этой характеристикой среды.

Рис. 11. Схематичное протекание переходного процесса над проводящей поляризующейся средой в экваториальной области источника для симметричной установки. ИТ - пропускание тока; СП - становление поля; ВП - вызванная поляризация;

ВПГ - гальванически вызванная поляризация; ВПИ - индукционно вызванная поляризация; $\mathrm{t}_{0}$ - время выключения тока; $\mathrm{t}_{2}$ - время смены знака поля при проявлении ВП

(ВПГ и ВПИ); $\mathrm{t}_{3}$ - время окончания измерений.

Рис. 12. Схематичное протекание переходного процесса над проводящей поляризующейся средой в осевой области источника на «больших» разносах. ИТ пропускание тока; РСПП - ранняя стадия переходного процесса; СП - становление поля; $\mathrm{t}_{0}$ - время выключения тока; $\mathrm{t}_{3}$ - время окончания измерений.

Учитывая, что при совместном проявлении ВПГ и ВПИ, последняя не является преобладающей, даже при большем значении поляризуемости подэкранной толщи, по сравнению с поляризуемостью надэкранной толщи, для источника заземлённая линия влияние гальванически вызванной поляризации, для данной модели, превалирует над влиянием индукционно вызванной поляризационной составляющей, поэтому для разности потенциалов не отмечается смены знака. Для измерений в осевой зоне источника знак поля индукции и ВП одинаков, ВПИ проявляется в смене знака сигнала переходного процесса.

Проявление ВПИ и ВП в целом на такой установке будет зависеть от постоянной времени СП, разноса и, вероятно, продолжительности времени регистрации сигнала. При 
большом удалении приёмника от источника (рис. 12), на ограниченном временном диапазоне, ВП может вообще не проявиться.

Вид трансформанты P1 для неполяризующейся среды, поляризующейся в верхней части и поляризующейся под высокоомным экраном существенно различается трансформанта становится информативным инструментом для выделения временного диапазона превалирования сигнала связанного с ВПГ или ВПИ.

\section{ЗАКЛЮЧЕНИЕ}

Гальванически заземлённая линия в импульсном режиме пропускания тока в проводящей земле возбуждает индуктивный переходный процесс, ВПГ и ВПИ. Во время токового импульса в поляризующейся среде протекают процессы разделения зарядов различной природы. После прекращения этого воздействия начинаются обратные релаксационные процессы, проявляющиеся как ЭМ сигнал, регистрируемый измерителем совместно с ЭМ сигналом, связанным с диффузией вихревых токов внутрь проводящей земли. Вихревые токи, распространяющиеся внутри поляризующейся среды, также индуцируют процессы разделения зарядов, которые после их ослабления, а затем и затухания становятся обратными релаксационными процессами, также проявляющиеся как дополнительный ЭМ сигнал, регистрируемый измерителем. Это описание последствий импульсного воздействия заземлённой электрической линии на проводящую поляризующуюся землю показывает, что он сложнее, чем при таком же воздействии индуктивного источника. Сигнал, регистрируемый индуктивными приёмниками над поляризующейся землёй, содержит, по меньшей мере, индуктивную и поляризационную составляющую, возбуждаемую вихревым током. Сигнал, регистрируемый заземлённой электрической линией, содержит индуктивную и поляризационную составляющую, возбуждаемую как гальваническим, так и вихревым током. В сигнале поляризационной составляющей возможно проявление нескольких релаксационных процессов различной природы. Несмотря на сложность регистрируемого сигнала именно заземлённая линия чаще используется для изучения ВП, т.к. плотность гальванических токов, «заряжающих» землю, выше, чем у вихревых токов незаземлённого источника, а время воздействия определяется продолжительностью токового импульса, а не продолжительностью переходного процесса, как для индуктивного источника.

Интерпретация результатов численного моделирования позволила сделать несколько интересных, с практической точки зрения, заключений. Эффективная глубина с которой регистрируется отклик земли осевой установкой зависит от разноса - расстояния между источником и приёмником. На близком расстоянии (на малых разносах) глубинность исследования постоянным током небольшая и проявляется поляризация вызванная вихревым током, в виде смены знака сигнала переходного процесса на линии заземлённой в осевой зоне источника. При удалении приёмника от источника в осевой зоне (увеличении разноса) увеличивается эффективная глубина с которой поступает отклик постоянного тока и на схожем временном диапазоне влияние ВПИ уменьшается.

Важный результат расчётов - зафиксировано присутствие смены знака сигнала переходного процесса для измерителя в осевой области источника в присутствии среды для которой поляризация вызвана вихревым током. Это становится новым научным фактом, т.к. считалось [Моисеев, 2002], что отрицательные значения приобретает только вторая конечная разность сигнала переходного процесса. Здесь можно сделать вывод: для источника заземлённая линия в осевой зоне индукционно вызванная поляризация 
проявляется в смене знака сигнала $\Delta \mathrm{U}(\mathrm{t})$, а для 3-х электродной измерительной установки в смене знака второй конечной разности сигнала переходного процесса $\Delta^{2} \mathrm{U}(\mathrm{t})$ и трансформанты P1(t).

Для симметричной установки сигнал становления поля имеет противоположный знак первичному полю, а поле ВП и гальванической и индукционной природы совпадает по знаку с первичным полем.

Нужно подчеркнуть, несмотря на то, что вызванная поляризация возбуждается вихревым или гальваническим током природа сигнала ВПИ и ВПГ одинакова электрофизические, электрохимические и электрокинетические релаксационные процессы в многофазной гетерогенной геологической среде.

Вызывает интерес исследование проявления ВПИ и ВПГ для условий акваторий. Здесь водная толща представляет из себя проводящий, в зависимости от минерализации воды, неполяризующийся слой, который отделяет электроразведочную установку от проводящей поляризующейся геологической среды. В зависимости от мощности воды, глубины погружения установки, разноса и времени регистрации сигнала соотношение ВПИ и ВПГ будет различаться. Изучение оптимальных условий для изучения поляризуемости геологической среды вызывает практический интерес аквальной геоэлектрики.

\section{ЛИТЕРАТУРА}

Антонов Е.Ю., Шеин А.Н. Разделение эффекта становления и явления вызванной поляризации при зондировании поляризующихся сред методом переходных процессов // Сборник материалов международного научного конгресса «Гео-Сибирь-2007», 25-27 апреля 2007 г. Новосибирск: СГГА, 2006, с.231-218.

Аузин А.А., Зацепин С.А. О дисперсии диэлектрической проницаемости геологической среды (применительно к интерпретации материалов георадиолокации) // Вестник Воронежского Государственного Университета. Серия: Геология, 2015, №4, с. 122-127.

Вишняков А.Э., Лисицын Е.Д., Яневич М.Ю. Влияние временных параметров вызванной поляризации залежей углеводородов на переходные процессы электромагнитного поля // Техника и методика геофизических исследований Мирового океана. Сборник научных трудов - 1988, с. 124-132.

Губатенко В.П. Эффект Максвелла-Вагнера в электроразведке // Физика Земли. 1991, №4, с. 88-98.

Жданов М.С. Геофизическая электромагнитная теория и методы. - М. : Научный мир, 2012. - 680 с.

Каменецкий Ф.М. Электромагнитные геофизические исследования МПП. - М. : ГЕОС, 1997. - 162 с.

Каменецкий Ф.М., Тригубович Г.М., Чернышёв А.В. Три лекции о вызванной поляризации геологической среды. - Мюнхен : Вела Ферлаг, 2014. - 58 с.

Карасёв А.П., Птицын А.Б., Юдицких Е.Ю. Быстрые переходные процессы вызванной поляризации. - Новосибирск: Наука, 2005. - 291 с.

Кожевников Н.О. Быстропротекающая индукционно-вызванная поляризация в мёрзлых породах // Геология и геофизика, 2012, т. 53, № 4, с. 527-540. 
Кожевников Н.О. Поиск таликов методом ЗСБ в условиях интенсивного проявления индукционно-вызванной поляризации // Геология и геофизика, 2014, т. 55, № 12, с. 18151827.

Комаров В.А. Электроразведка методом вызванной поляризации. - Л. : Недра, 1980. -391 c.

Легейдо П.Ю., Мандельбаум М.М., Рыхлинский $\quad$ Н.И. Дифференциальнонормированный метод электроразведки при прямых поисках залежей углеводородов // Геофизика, 1995, № 4, с. 42-45.

Легейдо П.Ю., Мандельбаум М.М., Рыхлинский $\quad$ Н.И. Информативность дифференциальных методов электроразведки при изучении поляризующихся сред // Геофизика, 1997, №3, с. 49-56.

Легейдо П.Ю. Теория и технология дифференциально-нормированной геоэлектроразведки для изучения поляризующихся разрезов в нефтегазовой геофизике. Дис. на соиск. уч. ст. д. г.-м. н. - Иркутск : ИрГТУ, 1998. - 198 с.

Могилатов В.С. Импульсная электроразведка. - Новосибирс : НГУ, 2014. - 300 с.

Петров А.А. Возможности метода становления электрического поля при поисках углеводородов в шельфовых зонах // Геофизика, 2000, №5, с. 21-26.

Сидоров В.А. Об электрической поляризуемости неоднородных пород. // Изв. АН СССР. Физ. Земли, 1987, №10, с. 58-64.

Халлбауэр-Задорожная В.Ю. Процессы происходящие в горных породах при наложении электрического тока и разности потенциалов: вызванная поляризация. Вопросы естествознания, 2016. - 3(11). - с. 76-79.

Nabighian, M.N. Quasi-static transient response of a conducting half-space: An approximate representation // Geophysics, 1979, 44, p. 1700-1705.

Strack K.-M. Exploration with deep transient electromagnetics. - Elsevier science publishing Co, 1992. - 373 p. 
Рис. 1. Структура вихревых токов: а). для источника индуктивная петля; б). для источника заземлённая линия.

Рис. 2. Изолинии плотности вихревого тока в разные моменты переходного процесса (По Strack, 1992).

Рис. 3. Схема установки численного эксперимента. Измерительные линии в осевой $\left(\mathrm{M}_{1} \mathrm{M}_{2}, \mathrm{M}_{2} \mathrm{M}_{3}, \mathrm{M}_{3} \mathrm{M}_{4}, \mathrm{M}_{4} \mathrm{M}_{5}, \mathrm{M}_{5} \mathrm{M}_{6}\right)$ и экваториальной (MN) области источника (АB).

Рис. 4. Абсолютные значения сигнала переходного процесса на измерительных линиях, имеющих разнос 1500, 2500, 3500, 4500, 5500 м: а). Над неполяризующейся средой; б). Над средой поляризующейся в верхней части разреза; в). Над поляризующейся средой; г). Над средой поляризующейся под высокоомным экраном.

Рис. 5. Абсолютные значения сигнала становления на симметричной измерительной линии: а). Над неполяризующейся средой; б). Над средой поляризующейся в верхней части разреза; в). Над поляризующейся средой; г). Над средой поляризующейся под высокоомным экраном.

Рис. 6. Абсолютные значения сигнала становления от 4-х моделей на измерительных линиях, удалённых на: а). 1500; б). 2500; в). 3500; г). 4500; д). $5500 \mathrm{M}$.

Рис. 7. Абсолютные значения сигнала становления на 3-х электродных измерительных линиях $\mathrm{M}_{1} \mathrm{M}_{2} \mathrm{M}_{3}, \mathrm{M}_{2} \mathrm{M}_{3} \mathrm{M}_{4}, \mathrm{M}_{3} \mathrm{M}_{4} \mathrm{M}_{5}, \mathrm{M}_{4} \mathrm{M}_{5} \mathrm{M}_{6}$.

Рис. 8. Абсолютные значения переходной характеристики второй конечной разности потенциалов на 3-х электродных измерительных линиях $\mathrm{M}_{1} \mathrm{M}_{2} \mathrm{M}_{3}$, $\mathrm{M}_{2} \mathrm{M}_{3} \mathrm{M}_{4}, \mathrm{M}_{3} \mathrm{M}_{4} \mathrm{M}_{5}, \mathrm{M}_{4} \mathrm{M}_{5} \mathrm{M}_{6}$.

Рис. 9. Переходная характеристика трансформанты Р1 на 3-х электродных измерительных линиях $\mathrm{M}_{1} \mathrm{M}_{2} \mathrm{M}_{3}, \mathrm{M}_{2} \mathrm{M}_{3} \mathrm{M}_{4}, \mathrm{M}_{3} \mathrm{M}_{4} \mathrm{M}_{5}, \mathrm{M}_{4} \mathrm{M}_{5} \mathrm{M}_{6}$. 
Рис. 10. Схематичное протекание переходного процесса над проводящей поляризующейся средой в осевой области источника на малых разносах. ПТ пропускание тока; РСПП - ранняя стадия переходного процесса; СП становление поля; ВПГ - гальванически вызванная поляризация; ВПИ индукционно вызванная поляризация; $\mathrm{t}_{0}$ - время выключения тока; $\mathrm{t}_{1}$ - время смены знака поля при проявлении ВПИ; $\mathrm{t}_{3}$ - время окончания измерений.

Рис. 11. Схематичное протекание переходного процесса над проводящей поляризующейся средой в экваториальной области источника для симметричной установки. ПТ - пропускание тока; СП - становление поля; ВП - вызванная поляризация; ВПГ - гальванически вызванная поляризация; ВПИ - индукционно вызванная поляризация; $\mathrm{t}_{0}$ - время выключения тока; $\mathrm{t}_{2}$ - время смены знака поля при проявлении ВП (ВПГ и ВПИ); $\mathrm{t}_{3}$ - время окончания измерений.

Рис. 12. Схематичное протекание переходного процесса над проводящей поляризующейся средой в осевой области источника на «больших» разносах.

ПТ - пропускание тока; РСПП - ранняя стадия переходного процесса; СП становление поля; $\mathrm{t}_{0}$ - время выключения тока; $\mathrm{t}_{3}$ - время окончания измерений. 
Табл. 1

Модель «Без ВП» (из диссертации П.Ю. Легейдо)

\begin{tabular}{|c|c|c|c|}
\hline с & $\begin{array}{c}\rho, \\
\text { Ом·M }\end{array}$ & $\eta, \%$ & h, M \\
\hline 1 & 50 & 0 & 200 \\
\hline 2 & 1000 & 0 & 500 \\
\hline 3 & 20 & 0 & 200 \\
\hline 4 & 1000 & 0 & \\
\hline
\end{tabular}


Табл. 2

Модель «ВПГ» (из диссертации П.Ю. Легейдо)

\begin{tabular}{|c|c|c|c|c|c|}
\hline C & $\mathrm{OM}^{\rho}{ }^{\rho,}$ & $\eta, \%$ & $\tau, \mathrm{C}$ & б.p. & $\mathrm{h}, \mathrm{M}$ \\
\hline 1 & 50 & 2 & 0.5 & 0.5 & 200 \\
\hline 2 & 1000 & 0 & & & 500 \\
\hline 3 & 20 & 0 & & & 200 \\
\hline 4 & 1000 & 0 & & & \\
\hline
\end{tabular}


Табл. 3

Модель «ВПГ и ВПИ» (из диссертации П.Ю. Легейдо)

\begin{tabular}{|c|c|c|c|c|c|}
\hline C & $\mathrm{OM}^{\rho}{ }^{\rho,}$ & $\eta, \%$ & $\mathrm{~T}, \mathrm{C}$ & б.p. & $\mathrm{h}, \mathrm{M}$ \\
\hline 1 & 50 & 2 & 0.5 & 0.5 & 200 \\
\hline 2 & 1000 & 0 & & & 500 \\
\hline 3 & 20 & 50 & 0.5 & 0.5 & 200 \\
\hline 4 & 1000 & 0 & & & \\
\hline
\end{tabular}


Табл. 4

Модель «ВПИ» (из диссертации П.Ю. Легейдо)

\begin{tabular}{|c|c|c|c|c|c|}
\hline C & $\mathrm{OM}^{\rho}{ }^{\rho,}$ & $\eta, \%$ & $\mathrm{~T}, \mathrm{C}$ & б.p. & $\mathrm{h}, \mathrm{M}$ \\
\hline 1 & 50 & 0 & & & 200 \\
\hline 2 & 1000 & 0 & & & 500 \\
\hline 3 & 20 & 50 & 0.5 & 0.5 & 200 \\
\hline 4 & 1000 & 0 & & & \\
\hline
\end{tabular}




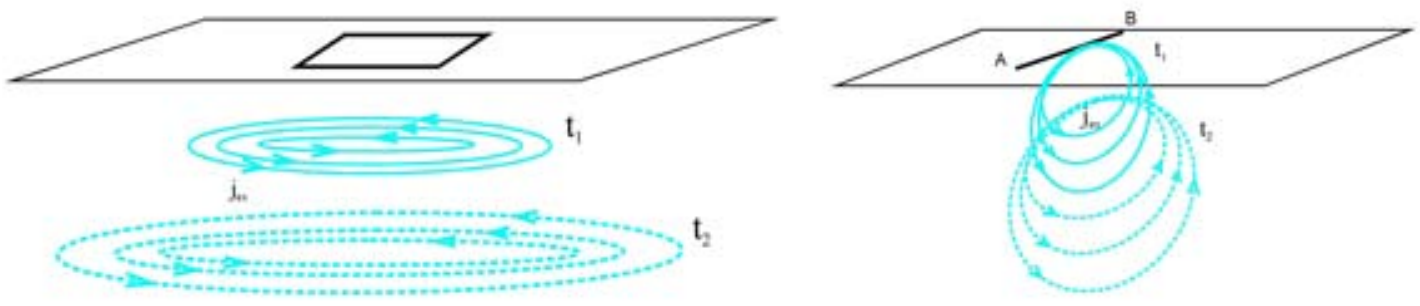


a).

\begin{tabular}{ll} 
& 0 \\
$\frac{I}{E}$ & $\mathrm{~km}$ \\
\hline & \\
& \\
&
\end{tabular}

$-6 \mathrm{~km}$

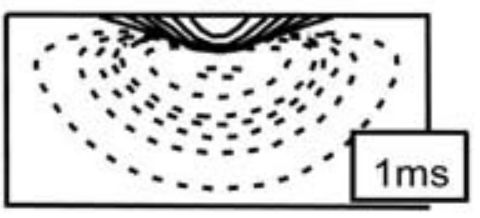

течение вихревого тока в направлении

ортогональном плоскости рисунка б).

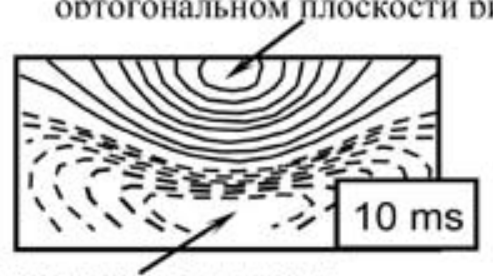

течение вихревого тока в

противоположном направлении

B).
В ранней стадии переходного процесса (РСПП) вихревой ток поддерживает структуру гальванического тока и имеет то же направление. Ниже возникает область, где вихревой ток течёт в обратным направлении для компенсации течения тока в области выше.

\section{Диффузия вихревого тока внутрь}

проводящей среды.

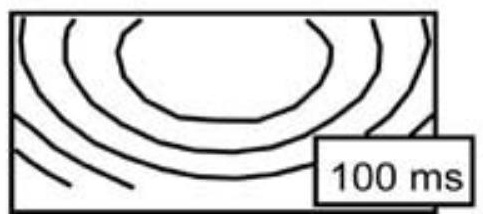

Стремление вихревого тока равномерному распределению проводящей среде. 


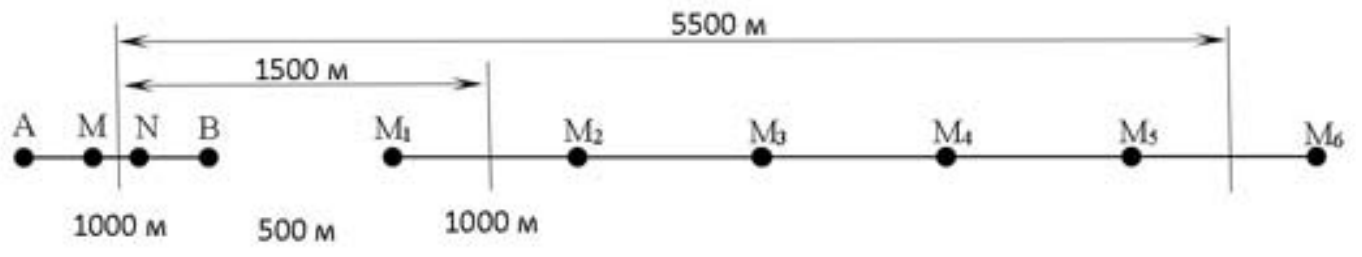



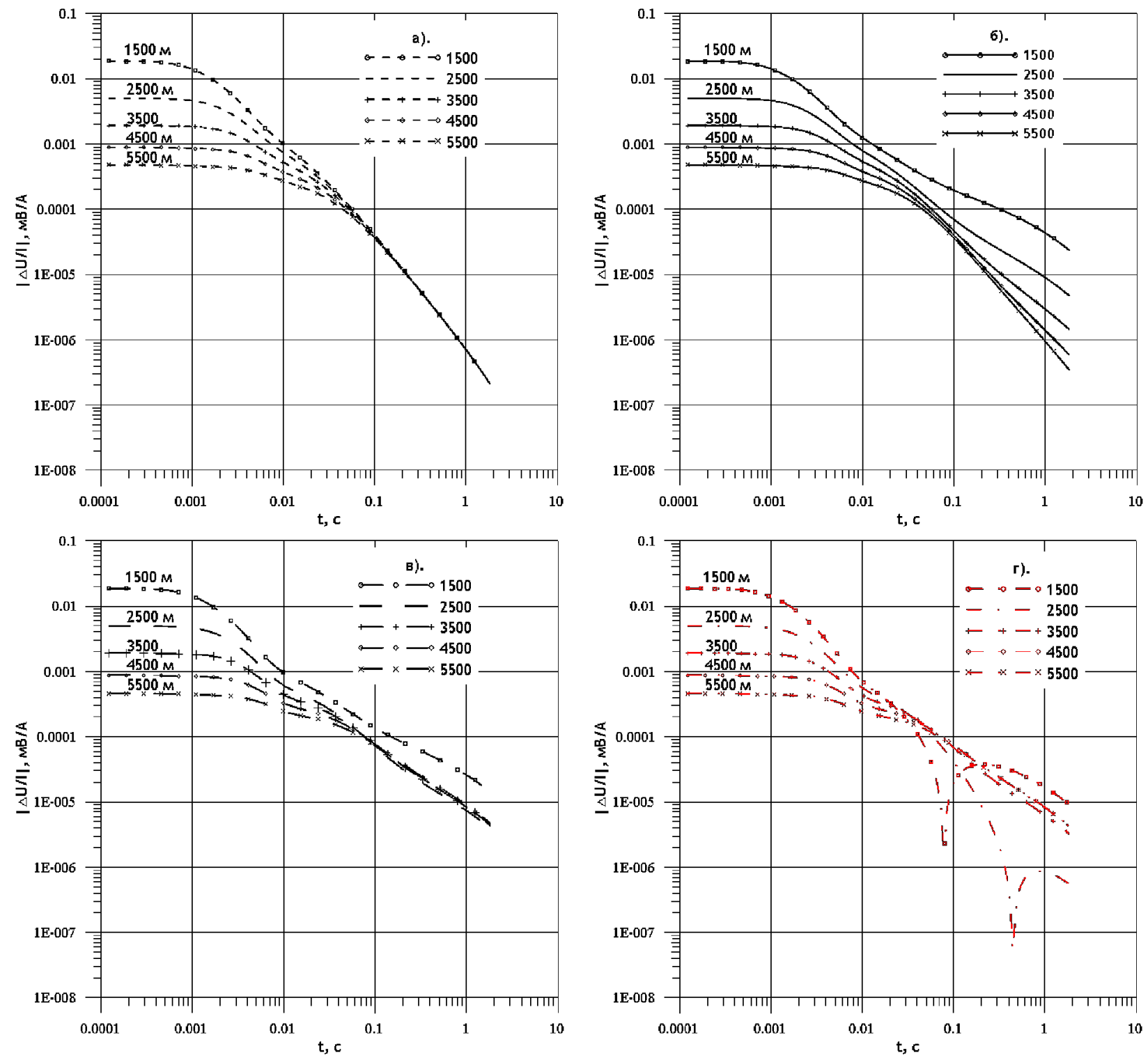


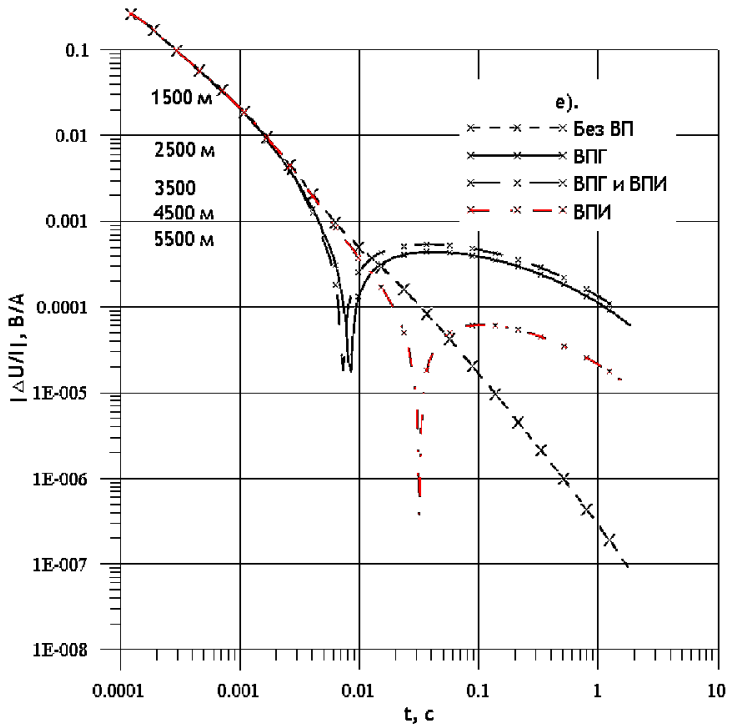




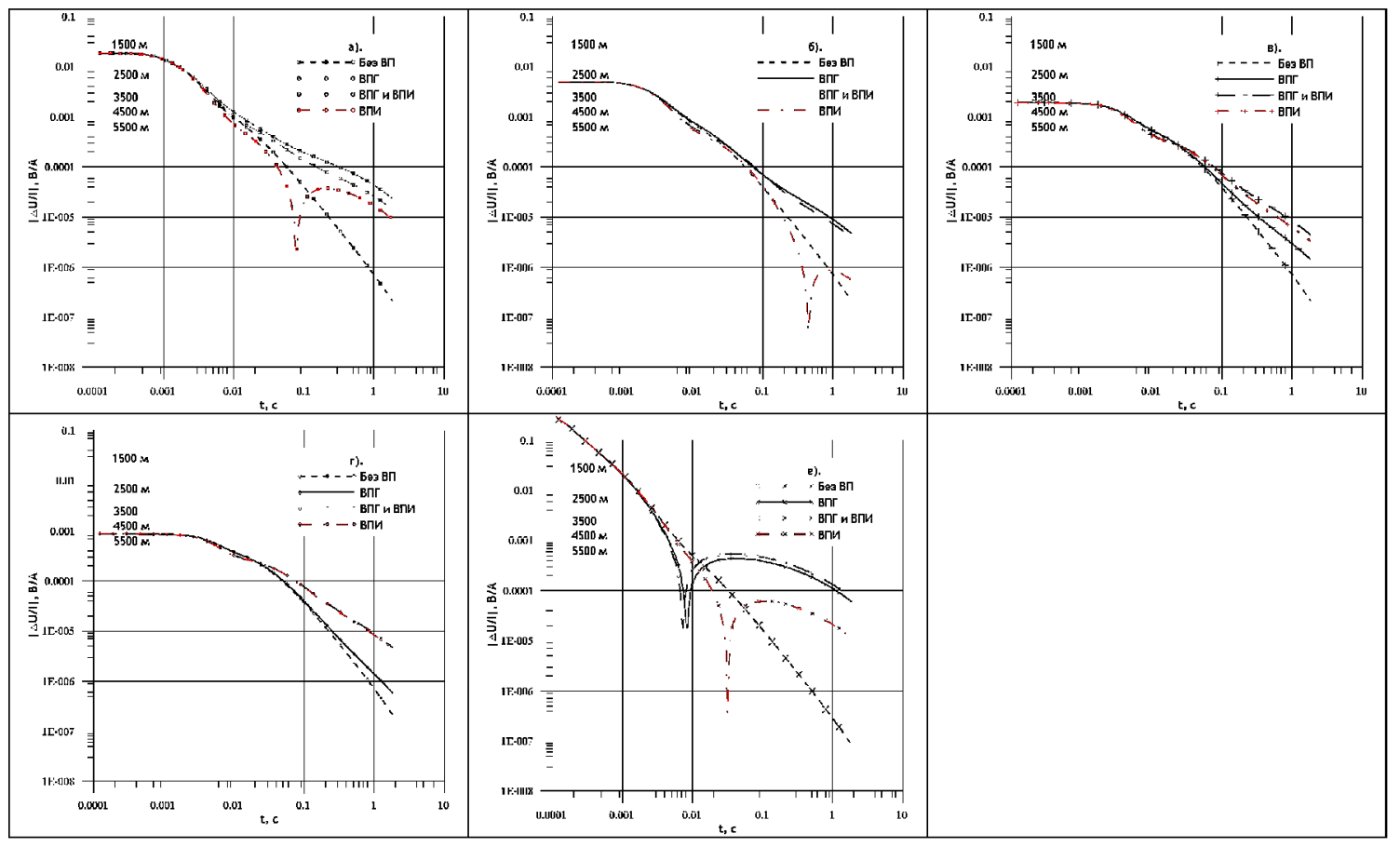



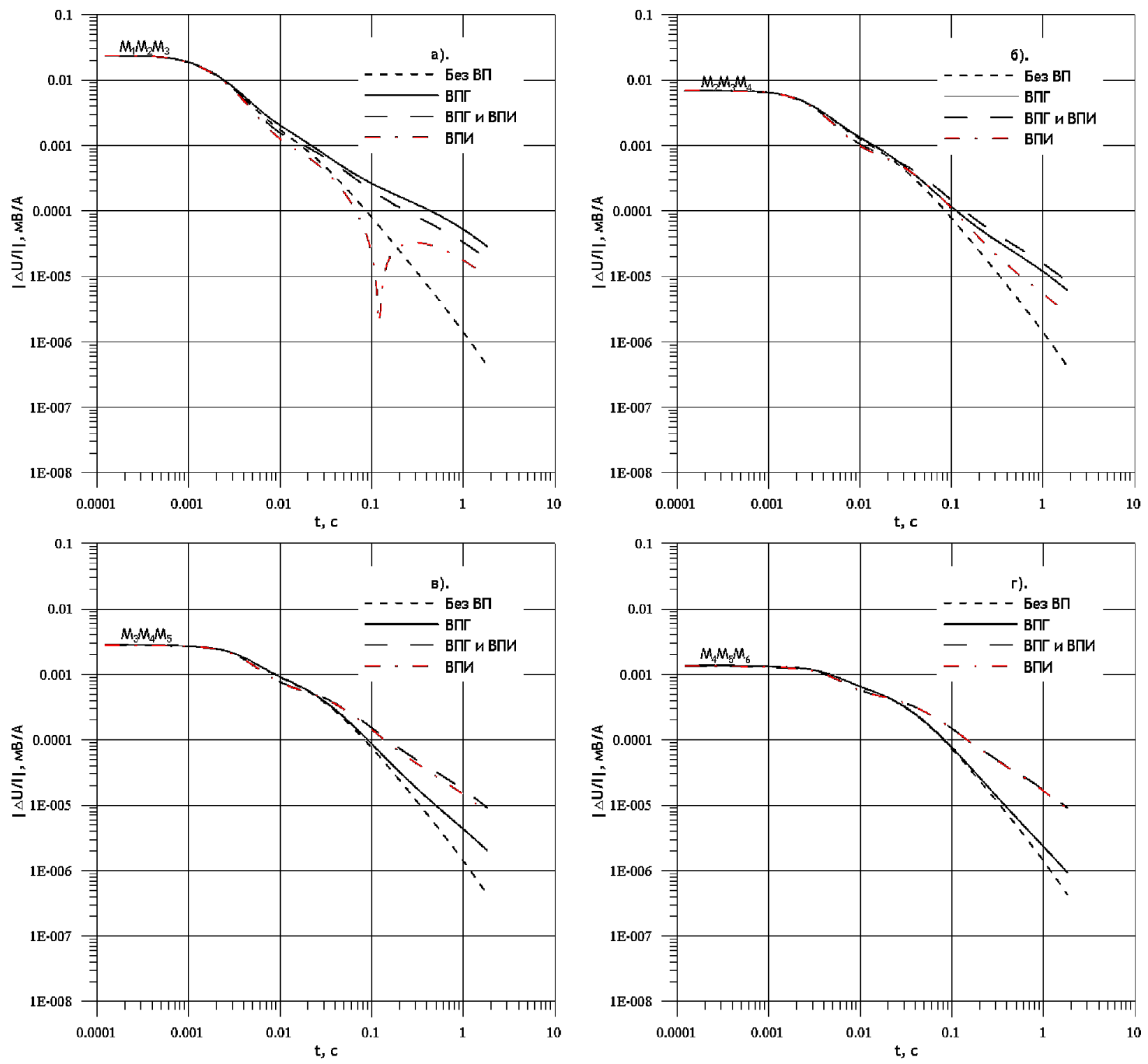

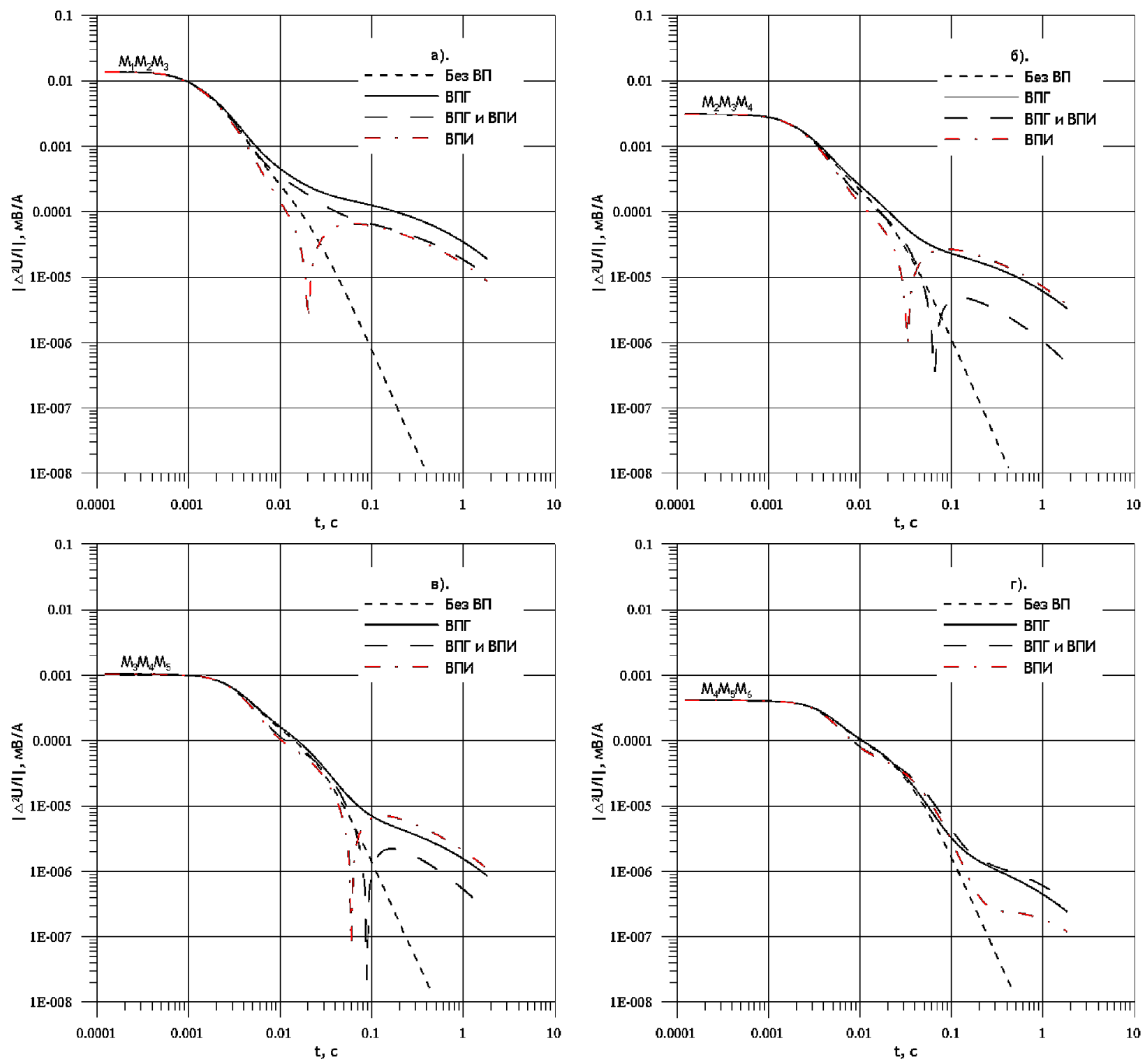

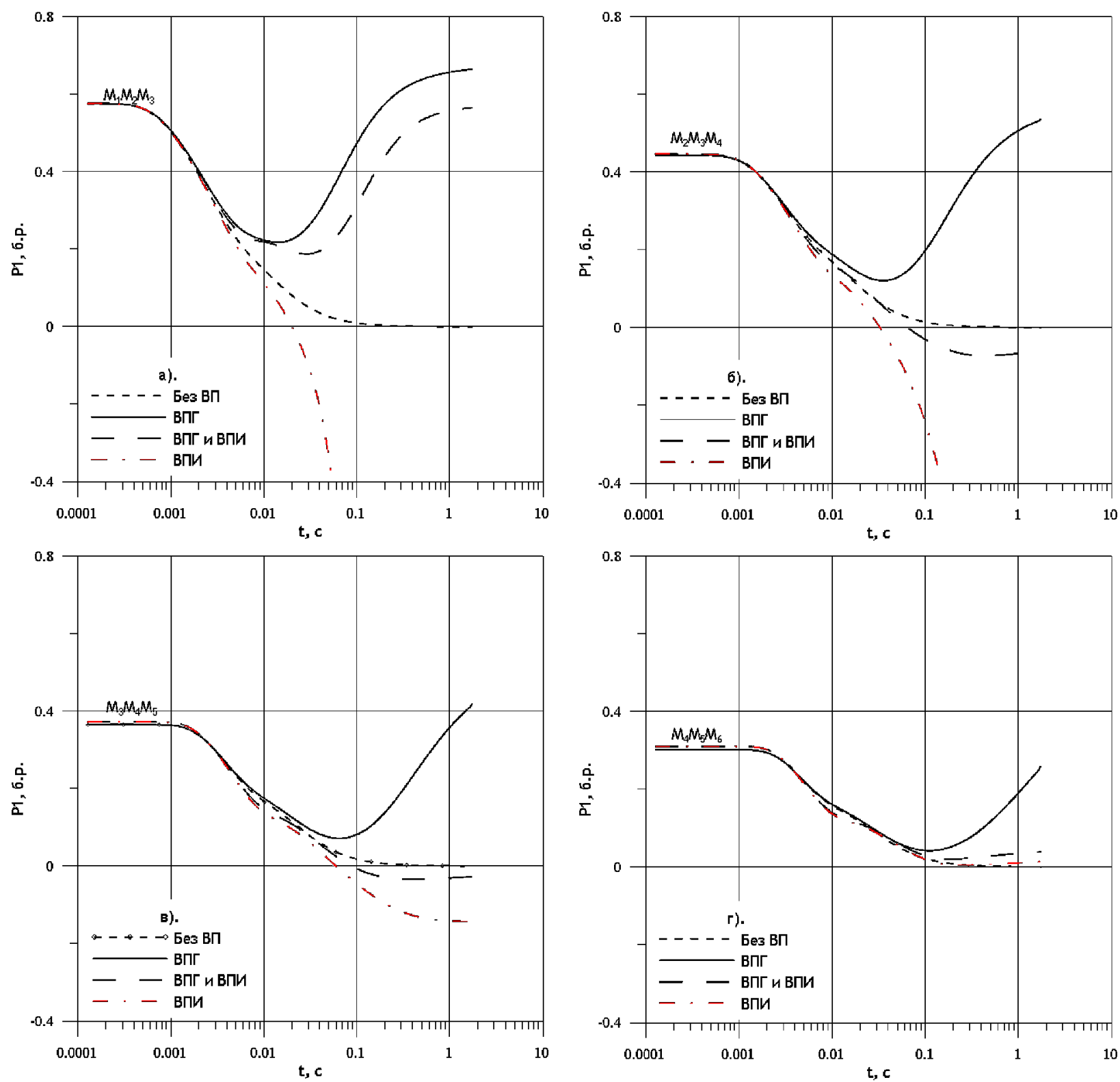

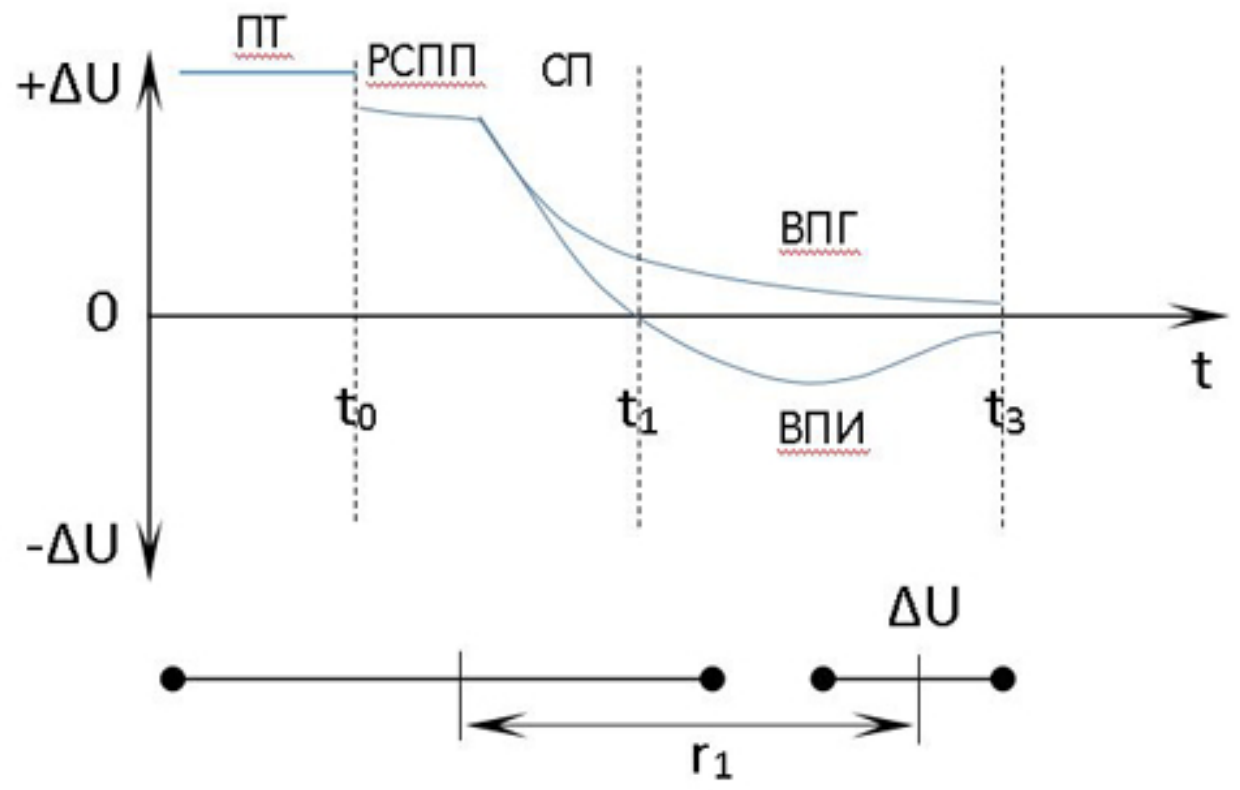


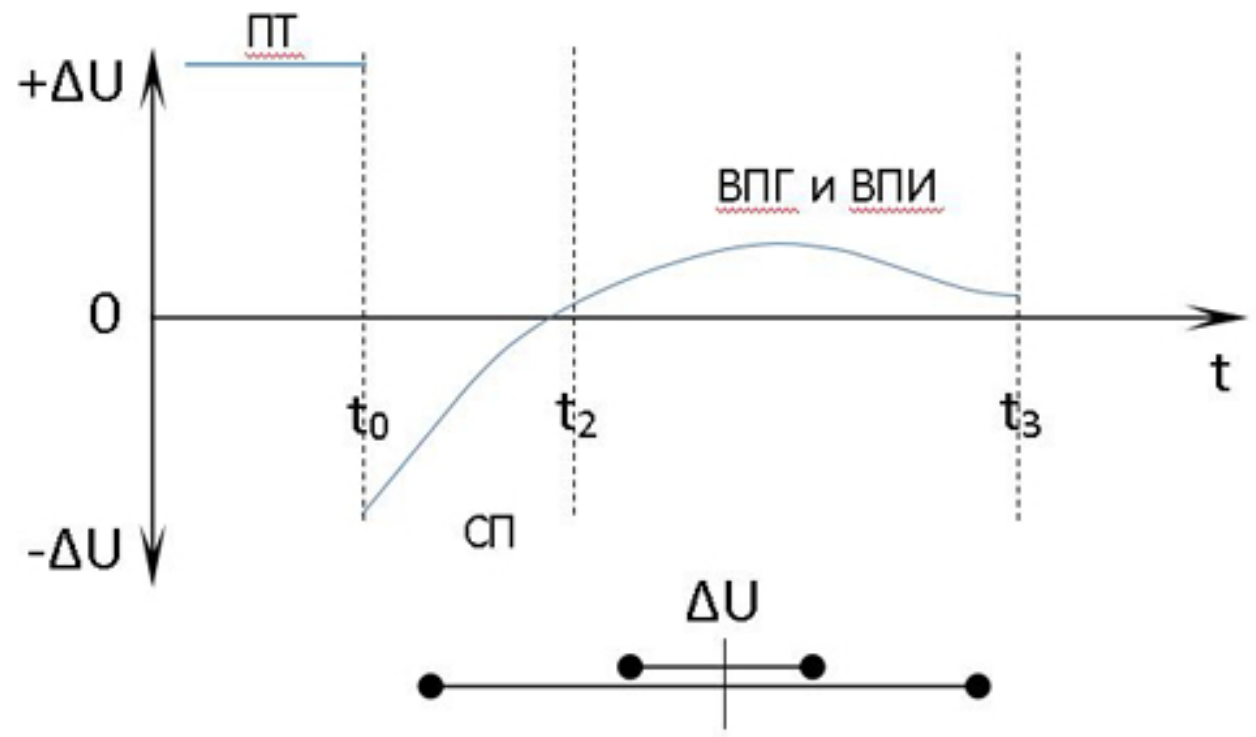




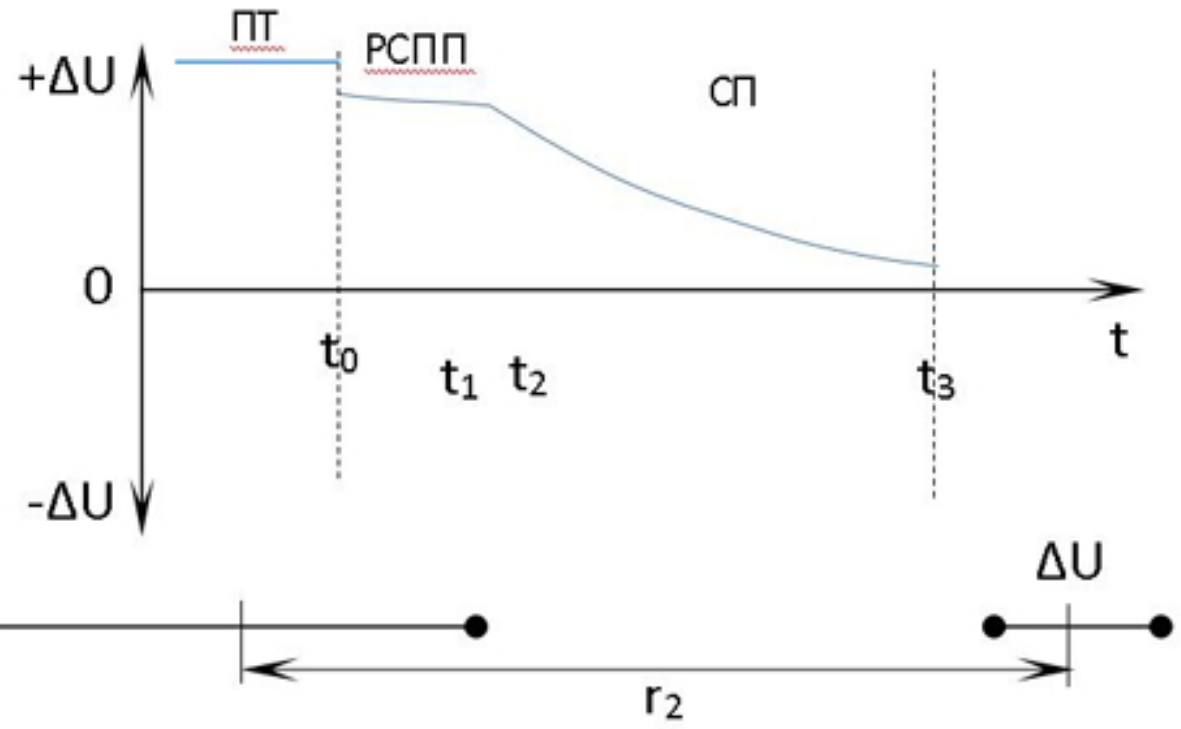

